\title{
Experiences of using a game for improving learning in software requirements elicitation
}

\author{
Ivan Garcia $^{1}$ | Carla Pacheco ${ }^{1}$ | Andrés León ${ }^{1}$ | Jose A. Calvo-Manzano ${ }^{2}$
}

${ }^{1}$ Universidad Tecnológica de la Mixteca, División de Estudios de Posgrado, Oaxaca, Mexico

${ }^{2}$ Universidad Politécnica de Madrid,

Escuela Técnica Superior de Ingenieros

Informáticos, Madrid, Spain

Correspondence

Ivan Garcia, Universidad Tecnológica de la Mixteca, División de Estudios de Posgrado, Oaxaca, Mexico.

Email: ivan@mixteco.utm.mx

\begin{abstract}
Many recent studies have demonstrated that the traditional methods used in teaching software requirements elicitation are ineffective because they frequently produce unskilled graduates who are inappropriately trained to apply their practical knowledge in the workplace. Therefore, the combination of traditional teaching approaches and modern learning tools has been used to better prepare undergraduate students. Biyubi is a game that has been developed to complement traditional teaching in order to facilitate the learning of requirements elicitation activities on an undergraduate Software Engineering course. Biyubi provides a simulated environment for students so that they can explore, analyze, and discover the wishes and needs of the correct stakeholders. This game has been tested and validated by undergraduate students from the NovaUniversitas University, Mexico. The use of Biyubi achieved an increase in the motivation, satisfaction, and learning experience of students in requirements elicitation. The game has the potential to better explain the proper use of a requirements elicitation technique while the technical skills of the students are also improved.
\end{abstract}

\section{1 | INTRODUCTION}

Effective education for students studying software requirements elicitation can be reinforced with the achievement of ludic activities. Students must learn, for example, how to observe and identify the correct stakeholders, communicate with them by applying the proper elicitation technique (or a combination of techniques), analyze, and classify the elicited information, as well as correctly identify the wishes and needs of the various stakeholders to acquire the skills required to perform the role of a professional analyst.

Despite research arguing against its ineffectiveness, "chalk and talk" is the main pedagogical technique used in engineering education [8]. It is true that theoretical lessons, which actively incorporate the "chalk and talk" concept in university classrooms, are suitable for presenting highly abstract concepts and factual information to undergraduate students. This is not the most suitable approach, however, for higher-cognitive objectives aimed at the application and transfer of knowledge to real-life situations, nor for encouraging a more active learning process [16]. This is a major problem for students because modern engineering disciplines, such as Software Engineering, require a highly practical environment that enables them to learn how to work on projects that are continually subject to any number of variables, such as clients, society, technology, government, and customers' rapidly changing requirements. The lack of a practical component reduces the opportunity for students to put into practice abstract elements and software requirements elicitation techniques.

The adoption of Game Based Learning (GBL) as an alternative learning method in Software Engineering courses is becoming increasingly popular $[2,43,25]$. GBL can be defined as the application of the principles of traditional 
games into real-life situations with the aim of obtaining the attention of students and encouraging the creation of knowledge [17]. Thus, the GBL concept broadly refers to the use of computer games to support teaching and learning. According to Reference [39], GBL provides a rich learning context to help students construct their own higher-level knowledge through vague and stimulating trial-and-error opportunities. In the context of Software Engineering education, the last few years has seen the application of GBL with the aim of improving motivation, commitment, and performance of students when learning the basic concepts of software development $[7,14,42]$. GBL has also been applied, to a lesser extent, to some software process areas such as Requirements Engineering, Project Management, Software Measurement, Testing, and other support areas [30].

With this in mind, we developed a new educational game to teach and support the proper application of an elicitation technique, called Biyubi. Biyubi is a word from the Zapotec language (an indigenous language from Mexico) meaning "explore, analyze, discover," and can be used to support learning when teaching requirements elicitation on a typical undergraduate Software Engineering course. The game simulates a real-world scenario in which students must interact and learn without the presence of a teacher during the game sessions. The rest of the paper is structured as follows: Section 2 provides the background for the motivation that led to the development of Biyubi. Section 3 describes the main characteristics and functions provided by Biyubi. In section 4 , the description of the materials and methods used for a case study are provided. The results are presented in section 5. Finally, section 6 summarizes the main conclusions of the study.

\section{2 | MOTIVATION}

The area of Requirements Engineering (RE) is defined as the process used to elicit the wishes and needs of stakeholders involved in the software development process in such a way that they can be transformed into software requirements that will be documented for their use in the subsequent stages of the software development lifecycle [31]. In the context of RE, requirements elicitation is a major process which helps analysts in discovering what the software must do through a solid understanding of the wishes and needs of the various stakeholders involved in the project. Therefore, requirements elicitation requires strong skills from Software Engineering students, with the aim of learning how to help the stakeholders and project team collaborate and achieve the project's objective $[23,46]$.

According to References $[1,6,20]$, the requirements elicitation process is frequently defined by three main activities: (1) stakeholder identification (i.e., the people who provide the information needed to identify the problem that needs to be solved as well as their needs and constraints); (2) obtaining the list of pre-requirements ${ }^{1}$ of each stakeholder by using the elicitation techniques; and (3) the integration, refinement, and organization of the collected information in order to determine the functionalities and limitations of the desired software. As human participation is essential for the elicitation process and because of the significant quantity of information that has to be handled, some problems may arise from an educational perspective.

The process of learning how best to elicit software requirements has been a recurring theme for the majority of undergraduate computing programs. For example, according to the Software Engineering 2014 (SE2014) Curriculum Guidelines for Undergraduate Degree Programs in Software Engineering [37], students must acquire the necessary knowledge to "demonstrate an understanding and appreciation for the importance of negotiation, effective work habits, leadership, and good communication with stakeholders in a typical software development environment."

Nevertheless, there is some core knowledge, such as requirements elicitation, that can only be covered once students have acquired some experience in the field. Students who do not have experience or communication skills in eliciting requirements may elicit requirements incorrectly and analyze them on a traditional course which incorporates a lot of "chalk and talk" teaching. Moreover, in accordance with SE2014, it is expected that students at undergraduate level acquire requirements elicitation competences on the cognitive levels of knowledge, comprehension, and application according to Bloom's taxonomy of educational objectives [3]. Undergraduate courses normally offer a range of opportunities to acquire requirements elicitation skills, but most courses follow conventional or traditional lecture/exercisebased approach. In fact, the methods for teaching requirements elicitation used by these conventional courses can be frequently influenced by students' misconceptions about what a software can or should do; lack of a definition for a systematic elicitation process; lack of student participation; poor communication between students; lack of common understanding; and the use of inappropriate, incomplete, incorrect, or ambiguous documentation [27].

One of the most difficult aspects of teaching software requirements elicitation is that this topic is often neglected and not taken seriously by undergraduate students in Software Engineering courses. Conventional teaching has added to this problem by decreasing interest among young students in this

\footnotetext{
${ }^{1}$ A pre-requirement (i.e., a preliminary version of the requirement) includes, for example, the stakeholder needs, system concepts, user expectations, and the system's environment. Therefore, a pre-requirement is a "requirement" before its transformation in a specification document, because requirements are formal technical specifications in the solution space [32].
} 
topic through the excessive use of theoretical classes. This may be due to traditional course structures which normally prioritize immediate code production. It is common to hear that "good" programmers may balance the poor requirements elicitation and that students are frequently encouraged to adopt these misinformed interpretations of software requirements while on a course, and worst still, during their professional lives. While it may be that students acquire a lot of technical knowledge about programming following this approach, the lack of attention to other requirements leads to other problems. Consequently, wrong practices become the norm, leading to project failure in the software industry.

In addition, research by Reference [7] stated that a common problem with conventional teaching is related to the difficulty of explaining the complexity of a software project, where it is not uncommon for requirements to be incomplete, contradictory, and constantly changing. Therefore, it is normal that Software Engineering courses that place an emphasis on theory produce unskilled professionals that cannot follow a disciplined approach for eliciting software requirements. Unfortunately, conventional teaching has also failed to engage students and reinforce concepts of software requirements elicitation because they are only supported by theoretical lessons (traditional classes with textbooks) and fail to provide practical and realistic experiences [9]. This conventional way of teaching has also contributed to an increasing lack of ability in a critical skill for requirements elicitation: collaboration.

Moreover, critical thinking is not encouraged by conventional approaches because realistic experiences are not provided by these courses, which in turn leads to students being ill-prepared in order to work as professional software analysts. Additionally, conventional methods do not provide any mechanisms for ensuring that students are intellectually engaged, meaning that they are often passive recipients resulting in RE knowledge being quickly forgotten [36]. These methods also assume that all students are at the same level of understanding and learn at the same pace when studying a specific elicitation technique.

In this context, GBL has become an alternative for training and education in software requirements elicitation with the aim of increasing motivation, commitment, and performance among undergraduate students. The following section documents the experiences of using a game for improving learning in software requirements elicitation at undergraduate level.

\section{3 | STRUCTURE OF BIYUBI}

According to Reference [47], under the GBL approach, game play involves interaction with a game through its rules, the connection between the player and the game challenges, and solutions, the plot and the student's emotional connection with the plot. Therefore, taking into account the suggestions of van Lamsweerde [40] to make the nature of RE more apparent and more concrete by representing the necessity of real world systems, we decided to create a university library scenario because it represents a familiar environment for the students. Thus, students play the game individually and they must interact with other characters. Each character assumes a specific role and represents a potential stakeholder as follows:

- Player. Student-based role for exploring the library with the aim of collecting a list of wishes and needs related to a new management system by interacting with various stakeholders, objects, and devices.

- Students. The main users of the library who can provide a considerable amount of information about it. Some students may share information after a short challenge has been completed by the player.

- Teachers. Teachers are frequent users of the library and can also provide valuable information about the way that the library works. Teachers can also share additional information after a challenge has been completed.

- Library staff. The staff has information about all the managerial activities, employees' responsibilities, documents, templates, procedures, and all the services provided by the library.

- Book suppliers. They can provide information about the process for buying and changing books and journals, a process to which the library must adhere.

- Others. These characters (e.g., security personnel, cleaning staff, visitors) do not provide any useful information to the player and on the contrary, they confuse players with ambiguous responses.

Biyubi aims to support the conventional way of teaching requirements elicitation at undergraduate level by providing a simulated environment with a real-word necessity that must be fulfilled by students. In Biyubi, therefore, the student must be a translator. He/she must understand what both the characters and other stakeholders are saying about the library, and then translate that knowledge into a preliminary version of the requirements for a system. Furthermore, throughout a game session, the student must complete several actions:

- Observe and learn the library's functions and operations, and understand them from the users' point of view.

- Interpret the library's functions and operations.

- Propose better ways of performing these functions and operations.

- Record the results in the form of a stakeholder-understandable wish or need.

The game is based on the traditional client/server architecture. The game design is shown in Figure 1. 


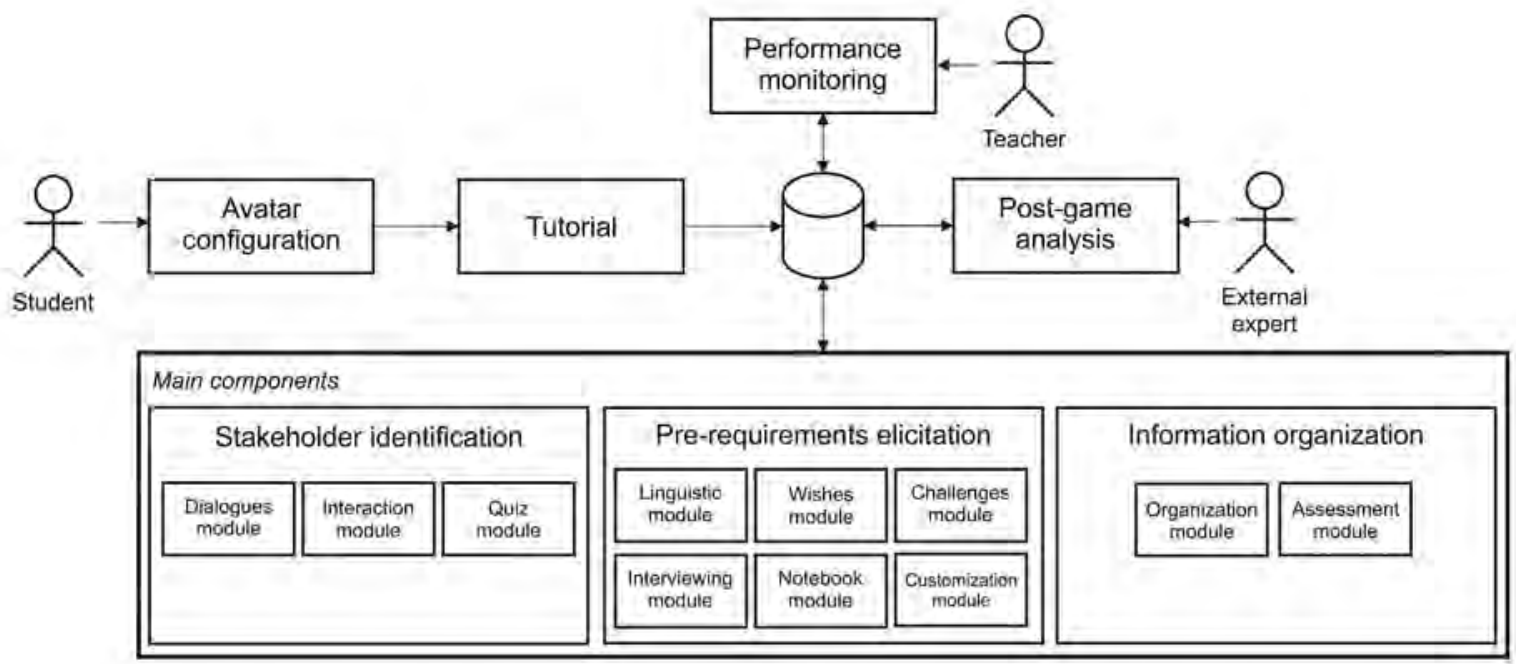

FIGURE 1 Internal components of Biyubi

First, the student has to create and configurate an avatar to play the game, which can then be customized according to the his/her achievements. Once the avatar has been created, the student is immersed in a tutorial so that he/she becomes familiar with the game's environment and keyboard controls. This tutorial includes the activities required to walk in the open world scenes, talk with a character, conduct an interview, identify linguistic patterns, use the notebook, and send the pre-requirements by using a terminal within the library. In addition, the internal architecture of Biyubi consists of three main components:

- The stakeholder identification component, which allows students to identify potential suppliers of wishes and needs. This component contains three modules: the characters' dialogues module that has been pre-loaded in Biyubi; the interaction module that provides a GUI to establish a conversation and obtain information from potential stakeholders; and the quiz module that enables the student, after having solved a puzzle, to find manuals, procedures, and information about an old system in the library which can be useful for obtaining additional pre-requirements.

- The pre-requirements elicitation component, which implements the elicitation process for the stakeholders once they are identified. This component contains six modules: the linguistic patterns module that helps students to learn to identify new information after asking a question during the interview; the wishes and needs module which contains the set of previously loaded pre-requirements that must be found by students; the interviewing module that provides a GUI to conduct an interview with a stakeholder; the challenges module that enables students to take part in contests in order to obtain additional information from stakeholders (e.g., when a book supplier arrives at the library, the outfit of a possible stakeholder, the location of a useful document); the notebook module that provides a tool for documenting the information obtained from stakeholders at any time during the game session; and the customization module that enables student to improve the outfit of an avatar using the points obtained from his/her performance in the game.

- The information organization component, which handles all the information collected by a student during the game session. This component contains two modules: the organization module that provides a GUI allowing students to integrate, refine, and organize the information collected by the notebook module in order to create the list of prerequirements; and the assessment module that enables student to send this list to the teacher for evaluation.

As can be seen, Biyubi was designed to cover three learning objectives related to the three activities of the requirements elicitation process: 1) stakeholder identification, 2) apply an elicitation technique (interviews) to obtain the wishes and needs of stakeholders, and 3 ) integrate, refine, and organize the collected data.

Regarding the first learning objective, conventional teaching has difficulties imparting the fact that stakeholder cooperation is essential for building a shared understanding of the problem to be addressed by the system-to-be. Such cooperation is critical for obtaining complete, adequate, and realistic requirements. In this respect, our earlier research has systematically gathered and evaluated available evidence pertaining to stakeholder identification in requirements elicitation [28].

One of the îdentified categories was methods that include stakeholder assessment, suggesting that identification can be based on their relevance to the project (priority interests), their knowledge and skills, and their attitude toward the process. Therefore, in order to solve this educational problem, 
in Biyubi the proper selection of stakeholders is encouraged by a comprehensive understanding and exploration of the scenario and establishing a representative sample of stakeholders based on their roles, stakes, interests, and type of knowledge they can provide.

For each character in the scenario, students must observe their relevant position in the library, the relevance of their role in making decisions about the system-to-be, their level of domain expertise and exposure to perceived problems. Thus, the cleaning staff or the security personnel, for example, cannot provide valuable information about the library's functions and operations. On the other hand, teachers and students can be found in the study area of the library, but they may not be willing to answer any question until the students solve a challenge. These challenges are usually related to clues that enable students to find manuals or books of procedures in order to obtain additional information about the library.

Finally, once students have identified some stakeholders, they can approach them to interact. For example, the player can approach students when they are talking in order to hear them or to participate in the discussion. When a player approaches a character, the game provides instructions in order to help students to interact in a friendly manner (see Figure 2). It is worth mentioning that the correct identification of stakeholders enables students to gain reward points (score) with the aim of increasing their motivation to keep on playing.
Regarding the second learning objective, conventional teaching has also had difficulties imparting the effective use of elicitation techniques. Learning these techniques leads to one of the most difficult challenges of the requirements elicitation process: overcoming the communication barrier between students and stakeholders. In fact, this problem frequently arises because students might experience some problems conducting interviews, for example, which may be due to a lack of domain knowledge, cognitive limitations of the interviewee, inability to formulate the right questions to extract the relevant information, not knowing when elicitation can be stopped, among other reasons. With the aim of solving this educational problem, Biyubi is focused on supporting the learning on how to use one of the most common techniques: the interview $[4,11,12,29]$.

Therefore, before gaming, students must discuss the library's environment in the classroom and formulate a script of the interview in order to improve their domain knowledge. After this step, the skill is knowing which questions to ask to the appropriate stakeholder. With the aim of preparing the students with the correct usage of this elicitation technique, Biyubi has implemented the technique known as NeuroLinguistic Programming (NLP) for improving communication and teaching students to ask the right questions and listen to what interviewees are saying and arrive at an unambiguous common understanding [34].

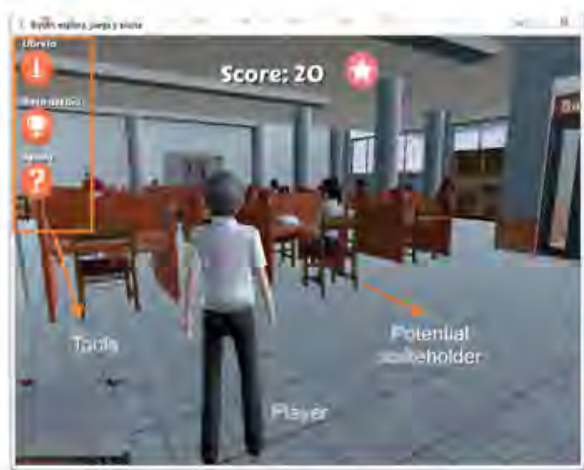

(a) Exploring the study area

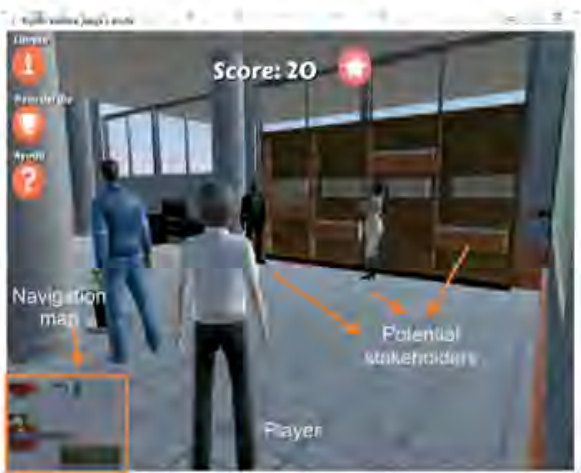

(b) Solving a challenge

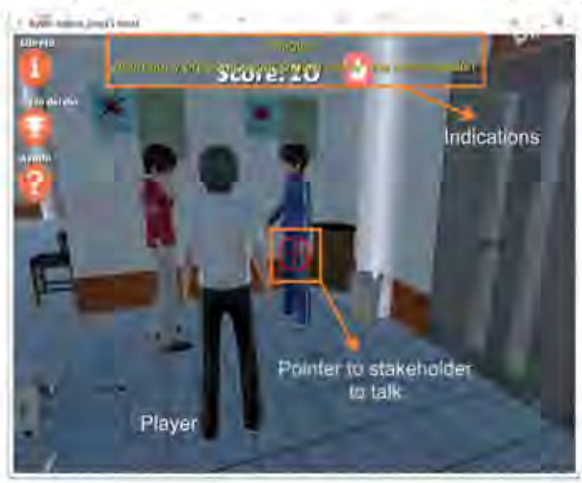

(c) Interacting with other characters

FIGURE 2 GUI elements for stakeholder identification: Starting with exploring the scene to making contact with a potential stakeholder 
The stakeholder responses can be listened to or read with the aim of facilitating the identification of linguistic patterns (see Figure 3). As with other adventure games, the student hears a whispering sound which indicates that a linguistic pattern may be identified, and a different question will be triggered to obtain more detailed information about the original question. This may be the difference between a more complete list of pre-requirements and an incomplete one, because students can avoid triggering questions when considering the linguistic patterns as an analyst with little experience would do. Reward points are also obtained by each pattern identified during the interview.

The output of the requirements elicitation process typically consists of a draft proposal of pre-requirements describing the system-to-be, its surrounding organization, the underlying domain, the problems identified within it, the opportunities to be exploited, and alternative ways in which the problems might be addressed in view of such opportunities [26]. Conventional methods usually fail when teaching how to collect and refine the collected information in order to accomplish the third learning objective. Biyubi has tried to solve this educational problem by providing a digital notebook during the game session so that students can learn how to integrate, refine, and organize the elicited prerequirements.

At any point during the game, students can search the library for a desk with a personal computer and take a seat to review their notebooks (see Figure 4). At the same time, Biyubi encourages students to assess some of the quality attributes defined by Lauesen [21] for each elicited prerequirement: completeness (i.e., the pre-requirements required for defining the problem were collected from all the identified stakeholders), consistency (i.e., there are

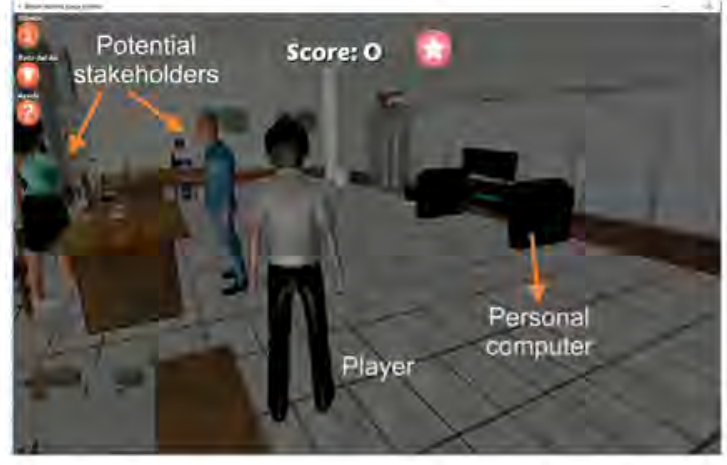

FIGURE 4 GUI elements for looking a computer to review the digital notebook

no pre-requirements in conflict), unambiguity (i.e., all the stakeholders have understood the same concepts), understandability (i.e., all the stakeholders clearly understood each pre-requirement), and non-redundancy (i.e., a pre-requirement was not repeated).

Once a student has completed these three learning objectives, the list of wishes and necessities is delivered for the teacher to review and generate immediate feedback. Meanwhile, students can perform different activities or play mini-games within the library until he/she receives the teacher's feedback. The game's narrative provides the context of a university Software Engineering course in which a teacher gives instructions to students to visit the university library with the aim of collecting information by interviewing the correct people. The game consists of exploring the animated environment (library's lobby, study area, and administration office) in order to conduct interviews with the correct stakeholders, solve stakeholders' challenges and daily challenges, and document their wishes and needs.

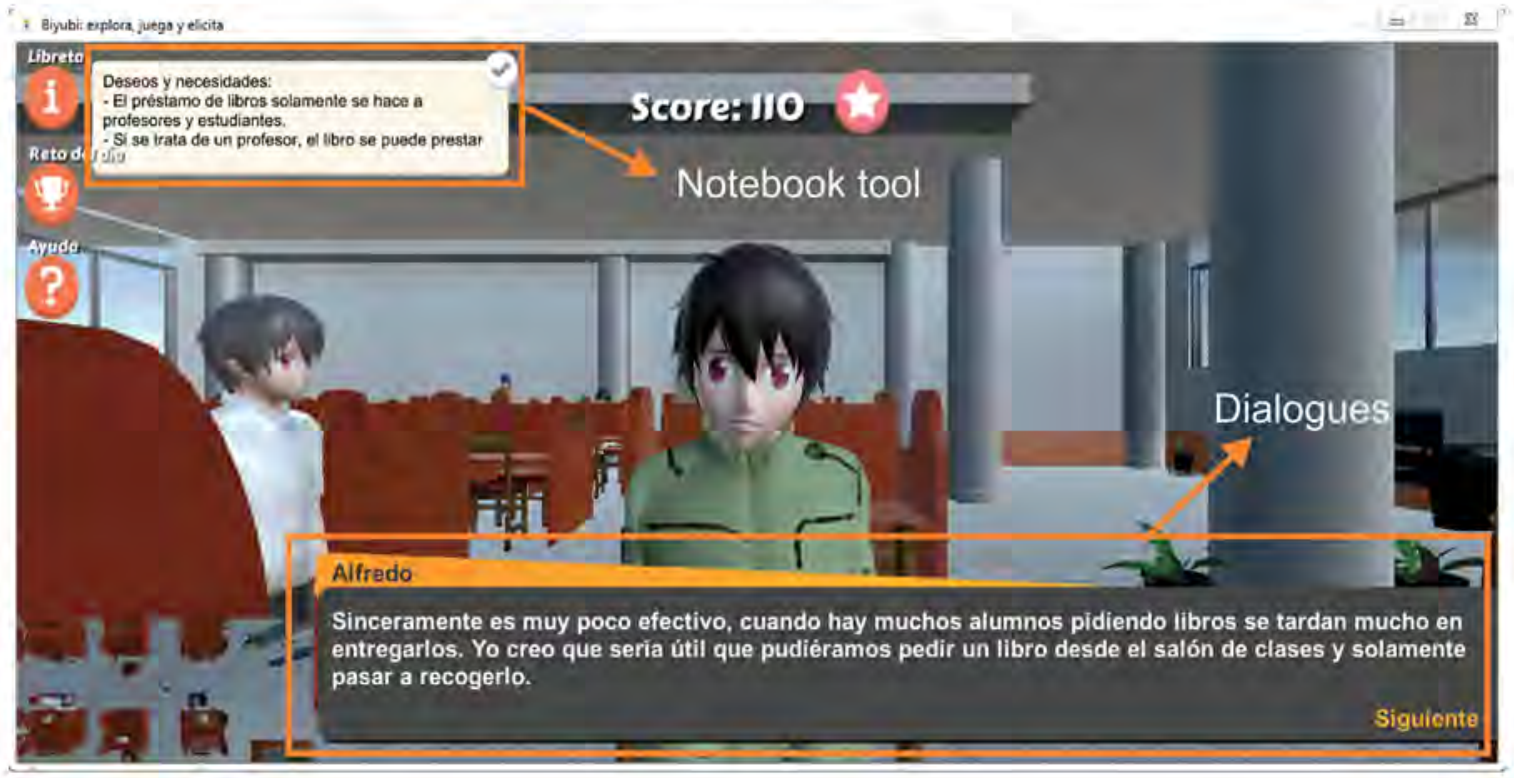

FIGURE 3 GUI elements for interviewing application 
Therefore, the game was also designed as an open world that students have to explore with the aim of interacting with several elements which can be potential stakeholders (e.g., people, manuals, book of procedures). The game activities are carried out with the aim of motivating students to collect the maximum number of pre-requirements in order to obtain reward points that they can then exchange in the library store for clothes and accessories to customize their avatars or clues to obtain more information. Finally, the collected reward points can be exchanged in the library store with the aim of customizing the avatar or obtaining some clues about additional useful information (e.g., the location of a character who may have important information, the location of a manual, a tip about when a potential stakeholder goes to the library). As previously stated, the solving of challenges can also provide similar information.

\section{4 | CASE STUDY: USE OF BIYUBI ON A SOFTWARE ENGINEERING COURSE}

\section{1 $\mid$ Research questions}

The aim of this study is to determine the impact of Biyubi on the motivation, satisfaction, and learning experience of undergraduate students in requirements elicitation. For this purpose, the research aims to investigate the following research questions:

RQ1: What is the impact of the game on undergraduate students' motivation, satisfaction, and learning experience in requirements elicitation?

RQ2: What is the impact of the game on undergraduate students' skills for eliciting quality requirements?

\subsection{Participants}

A total of 94 students from the fourth year of the Computer Engineering undergraduate program at the NovaUniversitas University, Mexico were included in the study. These students were divided into two groups: the experimental group (47 students), who used a computer game as part of a practical approach to the course, and the control group (47 students), who performed the same practical exercises following the traditional approach (i.e., using paper and pencil). The students were randomly selected and distributed between the experimental group and control group. Additionally, two professors with more than 15 years' experience teaching RE activities at undergraduate level and using requirements elicitation techniques in industry participated as external experts, observing both groups of students and analyzing the data collected by them.

\subsection{Research strategy}

In this study, the Biyubi game provides a simulated environment for students enabling them to explore, analyze, and discover the wishes and needs of the correct stakeholders. In other words, "they must elicit the requirements." Furthermore, the main objective of this game is to strengthen the comprehension and application of the requirements elicitation concepts and techniques. The Biyubi game was employed during the 2016-2017 academic year in the Software Engineering course of the undergraduate program on Computer Engineering at the NovaUniversitas University, Mexico. This course is focused on teaching students the common stages of the software development lifecycle, including the requirements elicitation process. As part of the course, students have to develop a final project with the aim of putting into practice the theoretical concepts learned in the classroom.

With regard to the requirements stage, however, the course does not provide enough practical work with elicitation techniques to collect quality requirements, and as a consequence, the delivered software does not frequently address the stakeholders' needs or, even worse, is never assessed. Therefore, we have introduced the game into the course with the aim of supporting the learning of the requirements elicitation activities by performing different and complementary practical exercises. With this aim in mind, we aim to assess if Biyubi clearly addresses the learning objectives established for this course, motivates undergraduate students to learn, and improves the learning of the requirements elicitation activities through fun and challenging experiences.

The experimental procedure starts with lessons for all students in which the theoretical concepts of requirements elicitation are provided, which is then followed by a practical exercise. The experimental group uses Biyubi to obtain a list of pre-requirements within the game's animated environment, while the control group performs the same task with real people in the NovaUniversitas library to get the same information. After the practical session, the external experts review the pre-requirements elicited by both groups with the aim of determining who identified more stakeholders, elicited more pre-requirements, used the linguistic patterns correctly, and obtained high-quality pre-requirements.

Following the practical sessions, students' perceptions are collected through a questionnaire after the practical session with the aim of evaluating the motivation of the learners, their perceptions of the learning experience, and their satisfaction in relation to the applied approach (Biyubi and traditional method). While it is true that the information obtained from students may be biased and untrustworthy, research by References $[15,33]$ has demonstrated that it also represents a simple, quick, and less intrusive alternative for obtaining 
rapid feedback with the aim of providing reliable, valid, and useful results.

\subsection{Instruments}

A standardized questionnaire of 18 items was designed to evaluate the students' motivation, satisfaction, and learning experience. This questionnaire is based on a 4-point Likert scale with the following response alternatives: "Strongly disagree" ( $\mathrm{SD}=1)$, "Disagree" $(\mathrm{D}=2)$, "Agree" $(\mathrm{A}=3)$, and "Strongly agree" $(\mathrm{SA}=4)$, which are converted to a numerical value to obtain a quantitative measure. The total number for each response is given and the mean $(M)$ for all responses is calculated for both groups of students. The 4-point scale was intentionally selected to eliminate the factor of indecision among students using "socially desirable elements" as a semiforced measure to allow students to choose one side (positive or negative) [45]. Regarding the impact on learning experience, the questions were designed to obtain the perceived knowledge level by both approaches (the traditional and Biyubi) after the practical exercise with respect to requirements elicitation activities as illustrated in Table 1.

\section{5 | RESULTS}

As previously stated, the study started with lessons for both groups of students with the aim of teaching the theoretical concepts of requirements elicitation. These lessons were focused on providing a detailed reference of the RE process, the requirements elicitation activities and techniques, how to design and conduct a formal interview, the definition of linguistic patterns to improve information collection, and the documentation of the collected responses. The lessons were conducted under the same conditions and given by the same teacher to students with similar backgrounds. Once the lessons had finished, we prepared a practical exercise to give students the opportunity to apply the concepts learned in the classroom with the aim of obtaining a starting point that could be compared from two different approaches: the control group would conduct the interviews in the real environment, and the experimental group would carry out the same task using the Biyubi game.

We used the game for two semesters (2016-2 and 2017-1) of the Software Engineering course of the Computer Engineering undergraduate program at the NovaUniversitas University, Mexico. A total of 94 students enrolled for the two semesters attended a 120-minute practical session. The data from this session was then collected and analyzed using descriptive statistics [35] to obtain the frequency distribution and central tendency of the students' responses, with the aim of identifying the positive and negative aspects of both approaches employed and considering the assessed dimensions. In the following sections, the results for evaluating these three dimensions will be presented.

\section{1 | RQ1: Students' motivation}

In general terms, both groups of students expressed high levels of motivation when carrying out the practical sessions with the aim of strengthening the theoretical concepts learned in the classroom (see Figure 5).

The students stated that the practical sessions were appropriate and stimulating for reinforcing the theoretical concepts learned in the classroom. The students also emphasized that the exercises allowed them to appreciate the importance of correctly understanding the wishes and needs of stakeholders in order to reduce the risk of a project's failure in a real context. Nevertheless, despite the fact that both groups of students mentioned that they understood the importance of correctly conducting the interviews, the results obtained for both groups were very different. For example, the control group was not motivated enough to apply this elicitation technique in a real environment because they felt that they had not received sufficient guidance in identifying the linguistic patterns during the interviews with the aim of learning how to use them. This may be due to the fact that students in the control group did not receive any help when conducting the interviews and faced the difficulty of interviewing people who were not willing to cooperate or responded in an abrupt manner to the questions.

In other words, the traditional environment did not provide enough support for learning how to deal with such people. Additionally, it is impossible for a teacher to work with all the students during each interview. The students in the experimental group, however, faced similar situations, but received the support of the mechanism inserted into Biyubi (i.e., receiving alerts that indicated a possible linguistic pattern and the solving of challenges to obtain additional information about the given answers) for triggering additional questions with the aim of learning how to use the patterns correctly (see Figure 6).

Consequently, students in the control group were unmotivated as they felt that their performance was unsatisfactory, as will be shown in the evaluation of the learning experience. Nevertheless, we believe that after some game sessions, these students will be able to conduct real interviews without problems.

\subsection{RQ1: Students' satisfaction}

The evaluation of this dimension provided quite different results from those previously described. There was a clear difference the between control and experimental groups in terms of the students' satisfaction (see Figure 7).

Due to the lack of support given during the interviews, students in the control group felt that they did not use the elicitation technique correctly and they needed the help of classmates to clarify any doubts during the practical session. However, this behavior only complicated the activity because more confusion was generated among the students 
TABLE 1 Questionnaire used to collect the students' perceptions of Biyubi

\begin{tabular}{|c|c|c|c|c|c|c|c|c|c|c|}
\hline \multirow[b]{2}{*}{ Items } & \multicolumn{10}{|c|}{ Students' opinions } \\
\hline & SD & D & A & SA & $\mathbf{A}$ & SD & D & A & SA & A \\
\hline \multicolumn{11}{|l|}{ Motivation } \\
\hline \multicolumn{11}{|l|}{$\begin{array}{l}\text { Q1. I am satisfied with the completed exercise because it represented a } \\
\text { stimulating challenge for me }\end{array}$} \\
\hline \multicolumn{11}{|l|}{$\begin{array}{l}\text { Q3. When completing the exercise, I understood the relevance of using an } \\
\text { elicitation technique correctly }\end{array}$} \\
\hline \multicolumn{11}{|l|}{ Q4. I enjoyed doing the exercise in the assigned environment } \\
\hline \multicolumn{11}{|l|}{$\begin{array}{l}\text { Q5. I achieved the goals of the exercise despite all the inconveniences that arose } \\
\text { during its development }\end{array}$} \\
\hline \multicolumn{11}{|l|}{$\begin{array}{l}\text { Q6. I am satisfied with my performance in correctly eliciting the wishes and } \\
\text { needs of stakeholders }\end{array}$} \\
\hline \multicolumn{11}{|l|}{ Q7. I was able to elicit a good mumber of wishes and needs during the exercise } \\
\hline \multicolumn{11}{|l|}{ Satisfaction } \\
\hline \multicolumn{11}{|l|}{ Q8. I felt confident applying the interviewing technique during the exercise } \\
\hline \multicolumn{11}{|l|}{$\begin{array}{l}\text { Q9. The presence of the teacher was not necessary during the exercise to resolve } \\
\text { any doubts about the elicitation technique }\end{array}$} \\
\hline \multicolumn{11}{|l|}{ Q10. I was able to interact with all the stakeholders in the assigned environment } \\
\hline \multicolumn{11}{|l|}{$\begin{array}{l}\text { Q11. I needed the help of my classmates to solve any doubts } 1 \text { had during the } \\
\text { interviews }\end{array}$} \\
\hline \multicolumn{11}{|l|}{ Q12. The educational approach I followed introduced an efficient way of learning } \\
\hline \multicolumn{11}{|l|}{$\begin{array}{l}\text { Q14. I felt confident that the approach employed enabled me to improve my } \\
\text { communication skills because I could lead the interview with the correct } \\
\text { questions }\end{array}$} \\
\hline \multicolumn{11}{|l|}{$\begin{array}{l}\text { Q15. The approach I followed enabled me to identify and analyze what was } \\
\text { important for stakeholders }\end{array}$} \\
\hline \multicolumn{11}{|l|}{$\begin{array}{l}\text { Q16. I felt confident that I had learned how to conduct an interview correctly after } \\
\text { completing the exercise }\end{array}$} \\
\hline \multicolumn{11}{|l|}{$\begin{array}{l}\text { Q17. After the exercise, I am conscious of the relevance of the loose relationship } \\
\text { between theory and practice }\end{array}$} \\
\hline Q18. I would like to follow the same approach for other courses in my program & & & & & & & & & & \\
\hline
\end{tabular}

by sharing incorrect information. As a consequence of poor motivation, students in the control group also argued that they could not interact with all the stakeholders in the university library. In fact, they only identified two roles out of the six defined by the simulation, while the experimental group identified all the roles. Finally, both groups of students agreed that the introduction of practical exercises introduced an efficient way of learning. We believe that the reason for this is because undergraduate students understand the relevance of practice to increase understanding of theoretical concepts. Nevertheless, a positive perception from the experimental group was perceived in the Biyubi game where a more independent behavior was also observed in résolving doubts.

\section{3 | RQ1: Students' learning experience}

For the evaluation of the last dimension, most of the students expressed an awareness about the loose relationship between theory and practice and confirmed that they were very interested in carrying out a set of exercises that enabled them to apply the learned concepts in real or simulated 

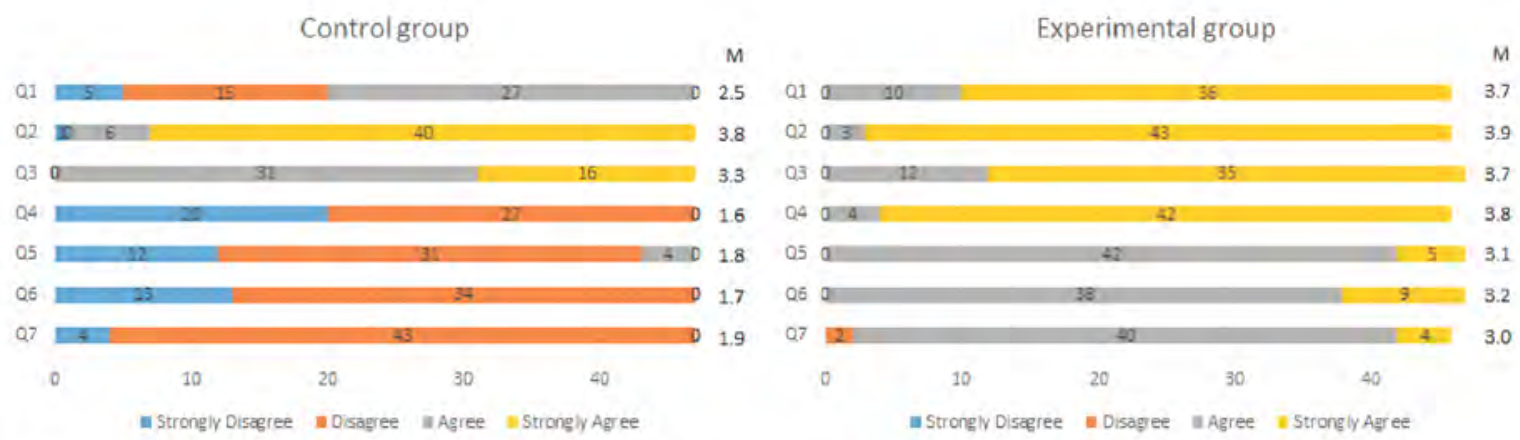

FIGURE 5 Frequency diagram with means for evaluating the motivation dimension
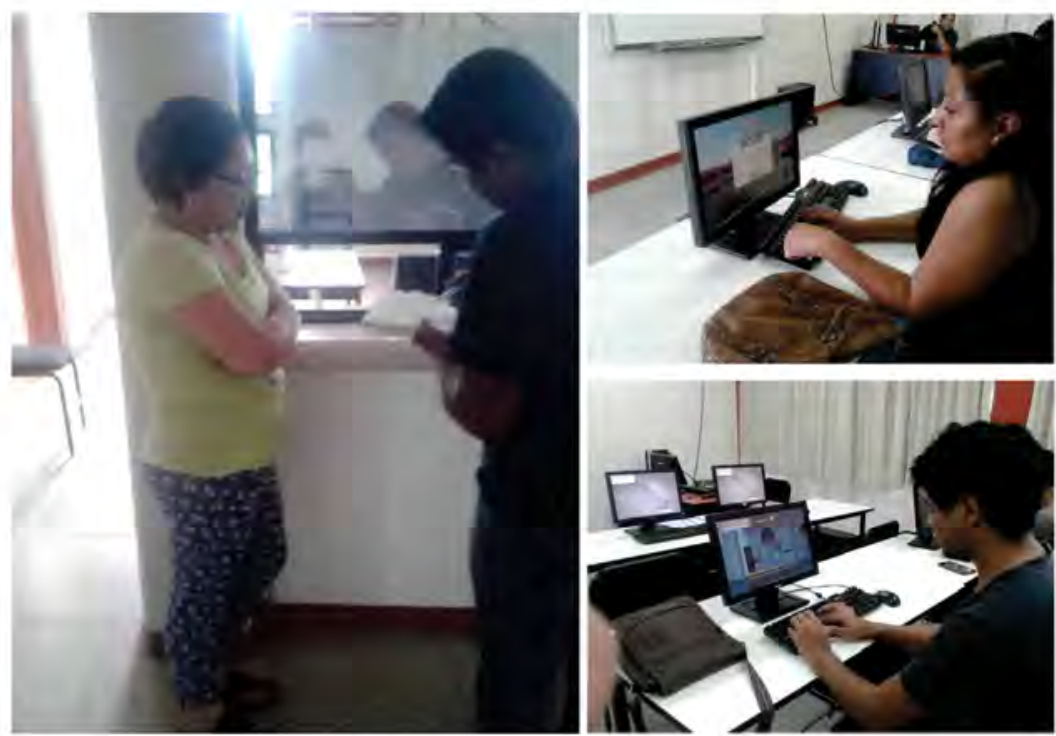

FIGURE 6 Example of practical sessions following traditional (left side) and game (right side) methods

environments. However, the observed learning outcomes were very different (see Figure 8).

This was confirmed by the students' responses with regard to increasing their confidence on their understanding of theoretical concepts learned in the classroom. Furthermore, the students stated that they were not able to identify what was important for stakeholders. In fact, after reviewing the lists of wishes and needs from both groups, the participating external experts confirmed that students in the control group obtained only $37 \%$ from a total of 70 pre-requirements available, while the experimental group could identify $82 \%$. It is worth noting that these results may have been influenced by the fact that, during the game sessions, students in the experimental group were in direct contact with the characters and they could observe them in more detail than students in the control group. It is obvious that the control group did not work in an
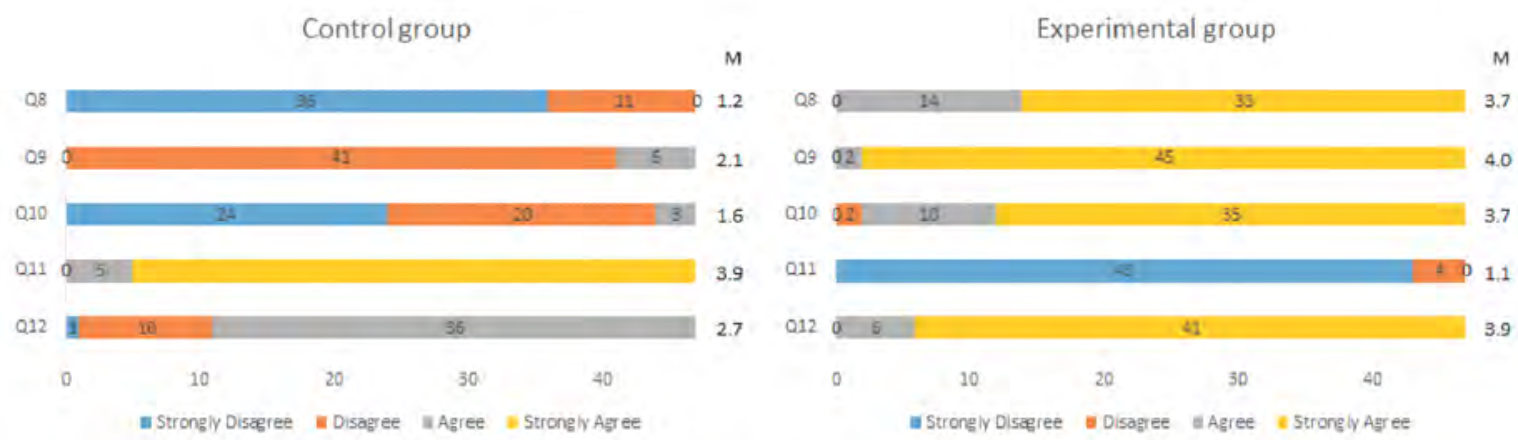

FIGURE 7 Frequency diagram with means for evaluating the satisfaction dimension 

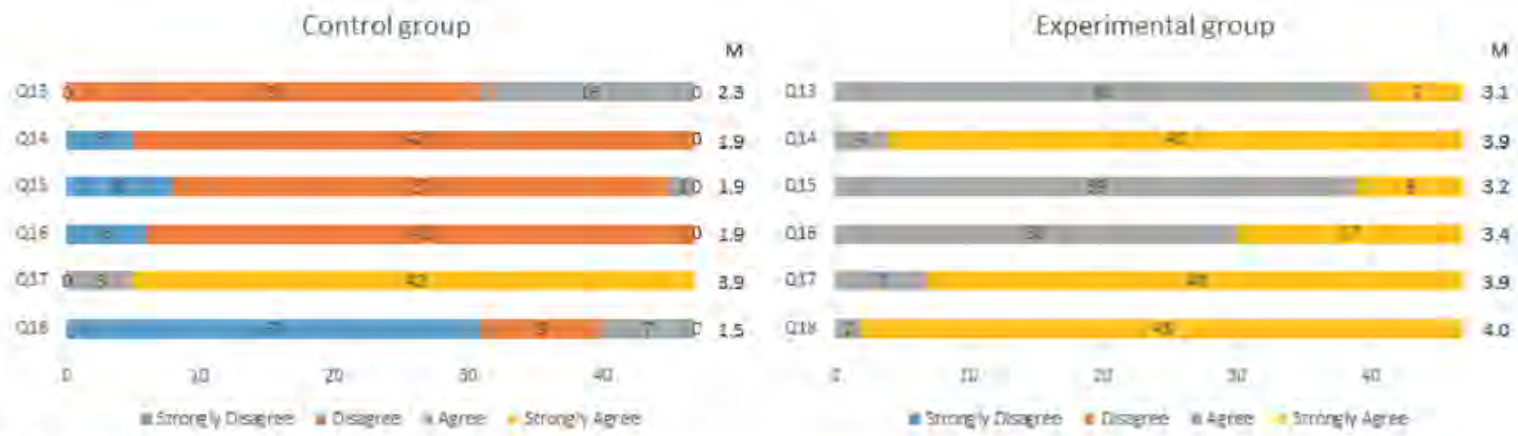

FIGURE 8 Frequency diagram with means for evaluating the learning experience dimension

environment which was favorable for observing people, and as a consequence, they were not able to establish the stakeholder identification with more precision, negatively affecting this activity. Nevertheless, it is clear that Biyubi provides a simulating environment that can avoid this type of problem generated by a traditional approach, where the students' work directly depends on the availability and willingness of people. Additionally, the experts' comments highlighted that the students in the control group only identified two of the seven linguistic patterns defined for the simulation used to trigger further specific questions and obtain detailed information from a stakeholder. The experimental group, however, identified and used six of the seven patterns which was evidently reflected in the number of elicited pre-requirements. The students in the control group also felt that they performed badly when trying to use the correct questions during the interview, and as a consequence, they felt that did not learn how to correctly conduct an interview to elicit information.

\subsection{RQ2: Students' skills to elicit quality requirements}

The external experts also reviewed the lists of pre-requirements delivered by both groups of students with the aim of evaluating Lauesen's quality attributes [21]. The pre-requirements elicited by the control group obtained the following scores: completeness (30\%), consistency ( $45 \%)$, unambiguity $(48 \%)$, understandability $(50 \%)$, and non-redundancy $(50 \%)$. On the other hand, the scores of the experimental group were as follows: completeness $(80 \%)$, consistency ( $85 \%$ ), unambiguity $(78 \%)$, understandability ( $82 \%$, and non-redundancy (90\%). These scores were evaluated considering the full lists of pre-requirements of each group. As can be seen, the students of the experimental group obtained better requirements using Biyubi. Therefore, we think that this improvement in the experimental group's performance is related to Biyubi's mechanisms for refining, analyzing, and organizing the list of wishes and needs of stakeholders (see Figure 9), supporting the students' work by guiding them with the analysis and classification of information. Unlike the control group, most of the students in the experimental group also demonstrated their interest in following the GBL approach for other courses of their undergraduate program.

Finally, considering the information collected for answering RQ1 and RQ2, the external experts also analyzed the students' performance regarding the execution of each activity of the requirements elicitation process taking into account the following items: number of roles identified, number of linguistic patterns identified, number of prerequirements elicited, and quality of the pre-requirements obtained during the practical exercise. Table 2 shows the data collected by the analysis with the aim of scoring the performance of both groups of students. It is worth mentioning that a higher average score was obtained by the experimental group, with a score of 10 considered an excellent performance and a score of 0 a poor performance.

\section{5 | Comparison of related computer games}

As was previously stated, RE education has become an important issue as researchers and practitioners become aware of the importance of providing professionals with the skills to successfully complete software projects. RE knowledge must be provided at undergraduate level before students become software engineers and are hired to develop real software projects [24]. Research by Reference [10], for example, argued that the objective of any RE course at undergraduate level is to provide students with the knowledge about the RE process and the existing tools and methods that must be applied in order to elicit, analyze, specify, validate, verify, and manage the software requirements for any project. RE education is usually supported by three main pillars: the basic skills that are provided by instructional material, knowledge about the current role of RE in the software industry, and a review of current research on RE.

Nevertheless, with regard to the practical components of courses, the main instructional method currently used in most universities is classroom-type instruction, in which the teacher presents materials to students using lectures or lecture/discussion presentation techniques that may be 


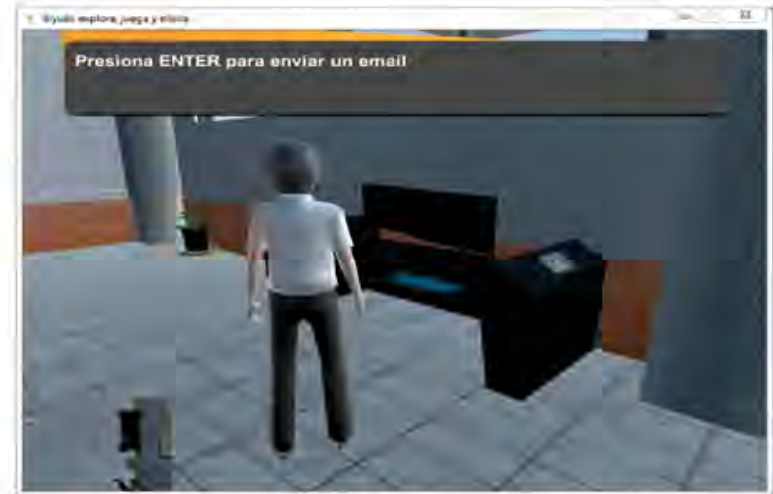

(a) Searching a computer

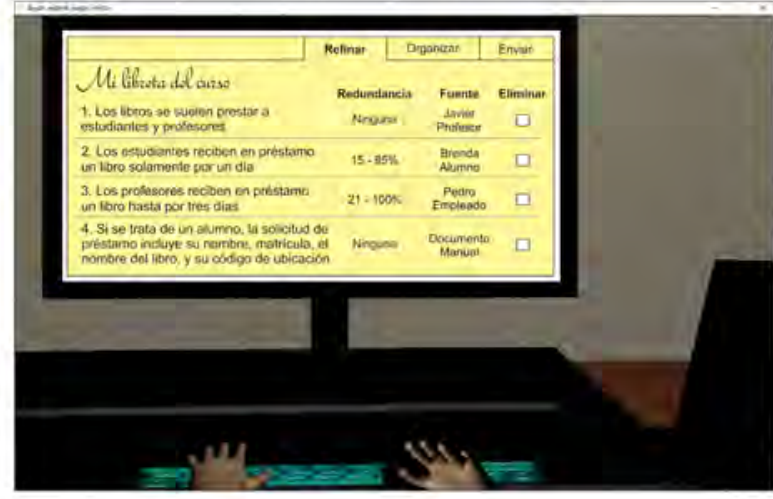

(c) Refining the information

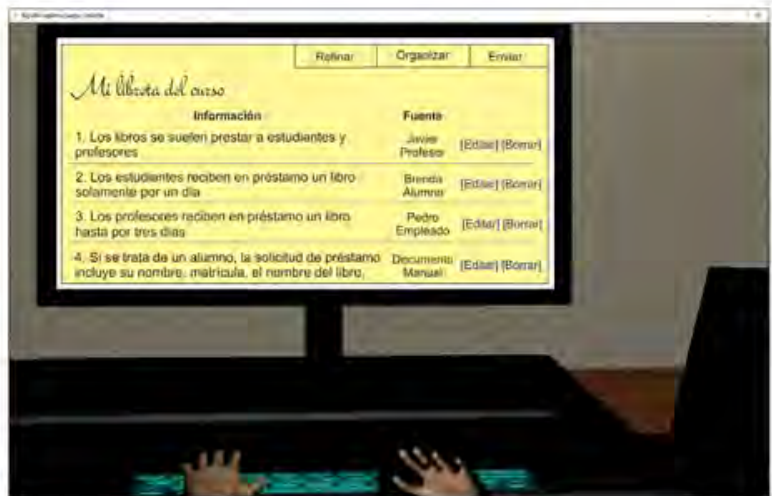

(b) Reviewing the notebook

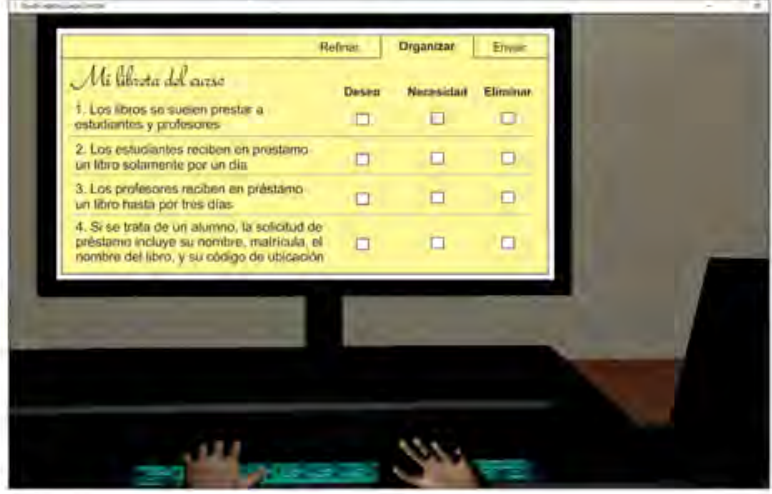

(d) Organizing the information

FIGURE 9 In-game phases for refining and organizing the elicited information: Starting from searching a computer to properly organizing the list of pre-requirements

complemented by relevant laboratory work. Furthermore, modern RE education is currently moving beyond the lecture format and exploring alternative approaches that can help students to learn more effectively, such as GBL. In this context, our results also included a comparison that summarized the existing computer games published in previous literature which were put forward as suggestions for use in teaching different RE processes. Although these games vary in type, they are beneficial for RE education at undergraduate level because they address the same problem: undergraduate students not understanding how requirements elicitation activities are related to the success or failure of software projects. Therefore, we compared these games with Biyubi in terms of their features for teaching requirements elicitation. The computer games are described in Table 3.
These computer games are focused on improving students' basic skills by simulating real-life situations in which they must elicit and analyze a set of wishes and needs from stakeholders. In these games, students typically take the role of analysts and make decisions about what can be a requirement, categorize the requirements into functional and non-functional, and prioritize and classify the collected requirements with the aim of learning how the misconceptions may affect a project's success. Most of these computer games are focused on supporting the teaching of the requirements elicitation process, as SE2014 recommends in the two essential topics for the eliciting requirements unit (i.e., elicitation sources and elicitation techniques). In this respect, the instructional design of these games has explored some elicitation techniques such as role playing, interviewing, observation, and workshops. However, detailed information is

TABLE 2 Analysis of external experts over data collected from practical exercise

\begin{tabular}{llll} 
Item & Target & Control group & Experimental group \\
\hline \# of roles identified (stakeholder identification) & 6 & 2 & 6 \\
\# of linguistic patterns identified (apply the elicitation technique) & 7 & 2 & 6 \\
\# of pre-requirements elicited (integrate, refine, and organize the collected data) & 70 & 26 & 57 \\
Quality attributes for each elicited pre-requirement (average) & $100 \%$ & $44 \%$ & $83 \%$ \\
Average score for practical exercise & & 3.5 & 8.7
\end{tabular}


TABLE 3 Existing computer games for supporting the teaching of requirements engineering

\begin{tabular}{|c|c|c|}
\hline $\begin{array}{l}\text { Computer } \\
\text { games }\end{array}$ & Context & Description \\
\hline UbiRE [22] & $\begin{array}{l}\text { Requirements elicitation and } \\
\text { analysis }\end{array}$ & $\begin{array}{l}\text { The objective of the game is to illustrate the RE concepts in the context of ubiquitous } \\
\text { systems. The player must obtain and analyze the requirements related to a customer } \\
\text { need for device connection (i.e., among devices, furniture, and accessories) within } \\
\text { the context of an intelligent house. }\end{array}$ \\
\hline i'Think [13] & Requirements elicitation & $\begin{array}{l}\text { The objective of the game is to improve the participation in a collaborative } \\
\text { requirements elicitation process, through which the player is rewarded not only by } \\
\text { the generation of new requirements, but also by the analysis of existing } \\
\text { requirements using several perspectives. }\end{array}$ \\
\hline $\begin{array}{l}\text { Role-play } \\
\text { game [5] }\end{array}$ & $\begin{array}{l}\text { Requirements elicitation and } \\
\text { analysis }\end{array}$ & $\begin{array}{l}\text { The objective of the game is to improve self-efficiency for students' learning in system } \\
\text { analysis. In the role of system analyst, the player must identify and analyze the } \\
\text { requirements of systems and identify them as being either functional or non- } \\
\text { functional. }\end{array}$ \\
\hline $\begin{array}{l}\text { GBL } \\
\text { application [14] }\end{array}$ & $\begin{array}{l}\text { Requirements elicitation and } \\
\text { analysis }\end{array}$ & $\begin{array}{l}\text { The objective of the game is for a team to manage and deliver a number of software } \\
\text { development projects. The player(s) assigned to the system analyst role must } \\
\text { identify and analyze the project's requirements. }\end{array}$ \\
\hline $\begin{array}{l}\text { The requirements } \\
\text { island [38] }\end{array}$ & $\begin{array}{l}\text { Requirements analysis, } \\
\text { validation, and management }\end{array}$ & $\begin{array}{l}\text { The objective of the game is to support the teaching of the RE discipline through the } \\
\text { solving of seven challenges that are executed in such a way as to allow the player to } \\
\text { pass through all the steps of the RE process. }\end{array}$ \\
\hline TREG [41] & Requirements elicitation & $\begin{array}{l}\text { The objective of the game is to teach RE using simulations and collaboration focusing } \\
\text { on the workshop technique, a collaborative way for eliciting and analyzing } \\
\text { requirements. }\end{array}$ \\
\hline $\begin{array}{l}\text { Software } \\
\text { Quantum [18] }\end{array}$ & $\begin{array}{l}\text { Requirements elicitation and } \\
\text { analysis }\end{array}$ & $\begin{array}{l}\text { The objective of the game is to make students aware of the importance of RE, } \\
\text { highlighting that when this process is carried out incorrectly, the final project will } \\
\text { most probably not satisfy the customers' expectations. }\end{array}$ \\
\hline Biyubi & Requirements elicitation & $\begin{array}{l}\text { The objective of the game is to provide a simulated environment to teach } \\
\text { undergraduate students to identify proper stakeholders, effectively conduct an } \\
\text { interview to obtain a list of pre-requirements and refine and organize the collected } \\
\text { information. }\end{array}$ \\
\hline
\end{tabular}

not provided about how these techniques were implemented into the game with the aim of meeting the learning objectives.

Additionally, with the exception of References [14] and [5], there is also a lack of empirical evaluations and objective evidence on the application of computer games for teaching the requirements elicitation process on undergraduate courses. From the educational perspective, and unlike the previous computer games, Biyubi has incorporated additional mechanisms with the aim of specifically improving the teaching of the three main activities of requirements elicitation.

For stakeholder identification, for example, students learn that identification can be based on the stakeholders' relevance to the project (priority interests), their knowledge and skills, and their attitude toward the process. Hence, the simulated environment of the game encourages players to identify and consult all likely sources of requirements taking into account the stakeholders' knowledge and skills and their understanding of the application domain (e.g., students, experienced staff, teachers), well-documented reports and manuals, old systems, and internal procedures or regulations.

With regard to conducting interviews correctly, the technique known as Neuro-Linguistic Programming (NLP) was incorporated into Biyubi for improving communication, teaching students to ask the right questions, to listen to what interviewees say so that students develop a clear, unambiguous understanding. The students have to then document the collected information in the Biyubi digital notebook during the game session with the aim of refining and organizing a list of pre-requirements.

\subsection{Threats to validity}

We are conscious that there are several threats with regard to the validity of the results presented in our study:

- Internal validity. In our study, internal validity issues primarily deal with the causal issues of our results. None of the students had knowledge of the preparation of this study in order to avoid modifying their traditional practices and thus preventing bias occurring in our evaluation. Nevertheless, we cannot be sure that the students of the experimental group were enthusiastic about the use of Biyubi, or whether this group had more intelligent students than the control group.

- Construct validity. Construct validity issues arise when there are errors in evaluation. We, therefore, collected 
quantitative and qualitative data in the requirements elicitation process carried out by the students to ensure that the results were the same regardless of the person analyzing the data. Nevertheless, the appropriateness of the game and the students' engagement are always difficult issues to evaluate, and as a consequence, and in the context of our study, these were analyzed through subjective evaluation. We reduced the impact of these threats by designing and applying a questionnaire for the evaluation of the game at undergraduate level considering the measurement instruments proposed by References [44] and [43], with the aim of carrying out the evaluation in a simple, quick, and non-invasive way.

On the other hand, it is worth mentioning that our study took into account a pre-defined set of pre-requirements previously loaded into Biyubi, and the performance of students was evaluated according to the percentage elicited from them. Using a problem statement only associated with, say, a library problem may result in biased results as we did not analyze whether the wishes and needs collected by the control group from real stakeholders correspond with this set of pre-defined pre-requirements. We have, therefore, tried to reduce this threat by asking external experts to evaluate the relevance of the pre-requirements elicited by both groups of students with the project's objective. Moreover, the quality attributes reflected by both sets of pre-requirements was also assessed by the external experts.

- External validity. It is possible that some external validity problems arose given the following characteristics of the study: the size of both groups of students, size, and complexity of the project assigned to students, and the project's application domain. Additionally, the results provided in this study cannot be generalized although we have repeated our evaluation on two courses over two semesters, as the only available courses are at NovaUniversitas given by the same teacher.

\section{CONCLUSIONS}

Teaching requirements elicitation with a focus on practical components within undergraduate courses must be an important part in the education of the future software engineers. As such, we have summarized the experiences of the use of a game when teaching the correct application of one of the most used elicitation techniques in the software industry: interviews. We focused our efforts on providing educational support to strengthen the theoretical concepts learned within classrooms by introducing the learning-theory foundations of GBL.

Furthermore, incorporated into the game is a simple method for stakeholder identification, resulting from earlier research [28], which introduces students to a comprehensive understanding and exploration of a simulated environment in order to determine roles, stakes, interests, and type of knowledge that characters can provide. Once stakeholders have been identified, the game also presented the use of NLP to help students with poor communication skills in learning how to identify linguistic patterns during the interview to obtain more information from stakeholders.

Similarly, the game teaches how to refine and organize the information collected in the interviews by using experiential learning [19]. This technique does not require the presence of a teacher and relates solely to the meaning-making process of the student's direct experience with gaining knowledge through both personal and environmental experiences.

It is also important to mention that experiential learning is one of the most common learning theories with GBL at undergraduate level [47]. Therefore, during a game session, students learn to identify who or what can provide them with information about the library, interview them and search for information in the environment to elicit wishes and needs, and then refine and organize the collected information to obtain a practical understanding of the requirements elicitation activities.

We have also presented the results from the evaluation of the Biyubi game demonstrating its potential to significantly increase student motivation and satisfaction, improve the learning experience taking into account the students' performance when they identify potential stakeholders, use the correct linguistic patterns during interviews, obtain a higher number of pre-requirements, and refine this information to give the teacher a set of high quality pre-requirements.

We also recorded an additional learning outcome: the students in the experimental group prepared a small number of questions before the game session and this number increased throughout the exploration of the environment. We therefore think that after various game sessions students could use this knowledge when conducting interviews in real software projects. Although few studies have been carried out on the learning effects of other computer games for teaching requirements elicitation at undergraduate level, our results are similar to those achieved in References [14] and [5]. These studies argued that GBL can be used to teach Software Engineering concepts when it is necessary to improve knowledge acquisition and student motivation through immersive experiences, and at the same time, their overall learning achievements. However, despite the fact that most computer games can be effective for learning different Software Engineering tasks, we should not generalize the effectiveness of Biyubi for a group of students who intend to learn the other activities related to the RE process (i.e., analysis, specification, validation and verification, and management) with the same game. We are currently 
exploring how to incorporate these activities within the game following the same GBL approach and evaluating the results through more exploratory studies.

Finally, although the students' perceptions and the evaluation of the external experts have provided us with promising results, we are conscious that we need more information to provide solid arguments on the benefits of our game. Therefore, we are currently collecting data on the use of Biyubi in other Software Engineering courses with different universities and teachers with the aim of extending its application in different contexts. Moreover, we are also conscious that some factors such as body language, time control, presentation and termination protocols, conflict management, improvisation, and adaptation can only be acquire when the elicitation technique is practiced with real people and in an environment not as controlled or directed as Biyubi's. Therefore, our future work is focused on addressing these factors in a second version of the game so as to improve the students' skills and ultimately, the quality of the obtained requirements.

\section{REFERENCES}

1. A. Abran et al., Guide the Software Engineering Body of Knøwledge (SWEBOK) (V3.0), IEEE Computer Society Press, Los Alamitos, CA, 2004.

2. F. Barreto, V. Benitti, and L. Sommariva, Evaluation of a zame used te teach usability to undergraduate students in computer science, J. Usability Stud. 11 (2015), 21-39.

3. B. S. Bloom (Ed.), Taxønomy of educational objectives: The classification of educational goals - Handbook I: Cognitive domain, McKay, New York, NY. 1956.

4. D. Carrizo, O. Dieste, and N. Juristo, Systematizing requirements elicitation technique selection, Inf. Softw. Technol. 56 (2014), 644-669.

5. C. H. Cheng and C. H. Su, A zame-based learning system for improving student's learning effectiveness in system analysis course, Procedia Soc. Behav. Sci. 31 (2012), 669-675.

6. M. G. Christel and K. C. Kang, Issues in requirements elicitation. Technical Report CMU/SEI-92-TR-012 or ESC-TR-92-012. Software Engineering Institute, Carnegie Mellon University. 1992.

7. T. M. Connolly, M. Stansfield, and T. Hainey, An application of games-based learning within software engineering, Br. J. Educ. Technol. 38 (2007), 416-428.

8. A. M. Connor, S. Karmokar, and C. Whittington, Frøm STEM t• STEAM: Strategies for enhancing engineering \& technology education, Int. J. Eng. Pedagogy 5 (2015), 37-47.
9. F. Dalpiaz and K. M. L. Cooper, Games for requirements engineers: Analysis and directions, IEEE Software, Early Access, 2018.

10. M. Daun et al., Project-based learning with examples from industry in university courses: An experience report from an undergraduate requirements engineering course, 6th International Workshop on Requirements Engineering Education and Training (REET), EEE Computer Society, pp. 9-13, 2016.

11. A. Davis et al., Effectiveness f requirements elicitation techniques: Empirical results derived from a systematic review, 14th EEE International Requirements Engineering Conference (RE'06), IEEE Computer Society, pp. 179-188, 2006.

12. O. Dieste and N. Juristo, Systematic review and aggregation of empirical studies on elicitation techniques, EEE Trans. Software Eng. 37 (2011), 283-304.

13. J. Fernandes et al., iThink: A zame-based approach towards improving collaboration and participation in requirement elicitation, Procedia Comput. Sci. 15 (2012), 66-77.

14. T. Hainey et al., Evaluation of a zame to teach requirements collection and analysis in software engineering at tertiary education level, Comput. Educ. 56 (2011), 21-35.

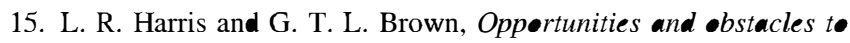
consider when using peer-and self-assessment to improve student learning: Case studies int teachers' implementation, Teach. Teacher Educ. 36 (2013), 101-111.

16. A. Johri and B. M. Olds, Situated engineering learning: Bridging engineering education research and the learning sciences, J. Eng. Educ. 100 (2011), 151-185.

17. K. Kiili, Digital game-based learning: Towards an experiential zaming model, Internet High Educ. 8 (2005), 13-24.

18. E. Knauss, K. Schneider, and K. Stapel, A zame for taking requirements engineering more seriously, Third International Workshop on Multimedia and Enjoyable Requirements Engineering (MERE 08), IEEE Computer Society, pp. 22-26, 2008.

19. D. A. Kolb, Experiential learning: Experience as the source of learning and development, Englewood Cliffs, NJ, Prentice-Hall, Inc, 1984.

20. G. Kotonya and I. Sommerville, Requirements engineering: Processes and techniques, Chichester, England, John Wiley and Sons, 1998.

21. S. Lauesen, Software requirements, styles and techniques, England, Addison-Wesley, 2002.

22. T. Lima et al., UbiRE: A game forteaching requirements in the context -f ubiquitous systems, XXXVIII Conferencia Latinoamericana en Informatica (CLEI), IEEE Computer Society, pp. 1-10, 2012.

23. L. Macaulay, Requirements engineering, London, England, Springer-Verlag, 1996.

24. R. N. Memon, S. S. Salim, and R. Ahmad, Analysis and classification of problems associated with requirements engineering education: Towards an integrated view, Arab. J. Sci. Eng. 39 (2014), 1923-1935.

25. A. L. Mesquida and A. Mas, Experiences on the use of a game for improving learning and assessing knøwledge, Comput. Appl. Eng. Educ. (2018), 1-13. https://doi.org/10.1002/cae.21990

26. H. Meth, M. Brhel, and A. Maedche, The state of the art in automated requirements elicitation, Inf. Softw. Technol. 55 (2013), 1695-1709.

27. S. Ouhbi et al., Requirements engineering education: A systematic mapping study, Require. Eng. 20 (2015), 119-138. 
28. C. Pachece and I. Garcia, A systematic literature review - f stakeholder identification methods in requirements elicitation, J. Syst. S•ftw. 85 (2012), 2171-2181.

29. C. Pachece, I. Garcia, and M. Reyes, Requirements elicitation techniques: A systematic literature review based on the maturity of the techniques, IET S•ftw. 12 (2018), 365-378.

30. 0. Pedreira et al., Gamification in seftware engineering-A systematic mapping, Inf. Softw. Technol. 57 (2015), 157-168.

31. K. Pohl, Requirements engineering: Fundamentals, principles, and techniques, Berlin, Germany, Springer Publishing Company, 2010.

32. R. Ravichandar, J. D. Arthur, and M. Perez-Quinones, Pre-requirement specification traceability: Bridging the complexity gap through capabilities. arXiv preprintcs $/ 0703012$. 2007.

33. D. Reinholz, The assessment cycle: A model for learning through peer assessment, Assess. Eva!. High. Educ. 41 (2016), 301-315.

34. S. Robertson and J. Robertson, Mastering the requirements process (2nd ed.), Boston, MA, Pearson Education, Inc, 2006.

35. P. Runeson and M. Host, Guidelines for conducting and reporting case study research in søtware engineering, Empir. Søftw. Eng. 14 (2009), 131-164.

36. $R$. B. Svensson and B. Regnell, Is role playing in requirements engineering education increasing learning outcome? Require. Eng. 22 (2017), 475-489.

37. The Joint Task Force on Computing Curricula IEEE Computer Society/Association for Computing Machinery. Software Engineering - Curriculum Guidelines for Undergraduate Degree Programs in Software Engineering. 2014.
38. R. Q. Thiry and G. Marcelle, Development of game to support the teaching of requirements engineering: The requirements island, SBGames, SBC, Florianopolis, Brazil, pp. 358-361, 2010. 39. R. van Eck, Six ideas in search of a discipline, B. E. Shelton, D. A. Wiley (eds), The Design and Use of Simulation Computer Games in Education, Rotterdam, The Netherlands, Sense Publishing, 2007, pp. 31-60.

40. A. van Lamsweerde, Requirements engineering. From system goals t• UML models to søtware specifications. Chichester, England, John Wiley \& Sons, 2009.

41. K. Vega, H. Fuks, and G. Carvalho, Training in requirements by collaboration: Branching stories in second life, 2009 Simposi॰ Brasileiro de Sistemas Colaboratives, IEEE Computer Seciety, pp. 116-122, 2009.

42. C. G.ven Wangenheim, R. Savi, and A. F. Bergatte,

DELIIER! - An educational game for teaching earned value management in computing courses, Inf. Softw. Technol. 54 (2012), 286-298.

43. C.G.ven Wangenheim, R. Savi, and A. F. Bergatte, SCRUMIAAn educational game for teaching SCRUM in computing courses, $J$. Sys. Softw. 86 (2013), 2675-2687.

44. C.G.ven Wanzenheim, M. Thiry, and D. Kechanski, Empirical evaluation of an educational zame on software measurement, Empir. Softw. Eng. 14 (2009), 418-452.

45. H. F. Weisberg, The total survey errer appreach, Chicage, University $\bullet$ Chicag・ Press, 2009.

46. K. E. Wiegers, Søftware requirements (2nd ed.), Redmond, WA, Microseft Press, 2003.

47. W. H. Wu et al., Investigating the learning-theory foundations of game-based learning: A meta-analysis, J. Comput. Assist. Learning 28 (2012), 265-279. 